\title{
Effects of Anxiety, Depression, and Stress on Sleep Disorder and Night Eating Syndrome in Adolescents: Results of an Internet Survey
}

Ummugulsum Gundogdu ( $\square$ glsmgndgd2@yahoo.com )

Bolu Izzet Baysal State Hospital https://orcid.org/0000-0001-6327-4808

Research Article

Keywords: sleep quality, depression, anxiety, stress, night eating syndrome

Posted Date: January 5th, 2022

DOI: https://doi.org/10.21203/rs.3.rs-1223540/v1

License: (c) (i) This work is licensed under a Creative Commons Attribution 4.0 International License. Read Full License 


\section{Abstract}

Purpose

The current study examined how sleep quality is related to night eating syndrome (NES) via the indirect effects of anxiety, depression, and stress to determine the mechanism of its development.

Methods

This cross-sectional web-based study included 171 adolescents aged $12-18$ years (55.0\% girls). Participants completed the self-report Night Eating Questionnaire (NEQ), Scales for Outcomes in Parkinson's disease (SCOPA) Sleep Scale, and Depression, Anxiety and Stress Scale-21 items (DASS-21).

Results

The results showed that anxiety, depression, and stress directly influenced the NEQ. AMOS path analysis was used to examine whether these also had an indirect influence on the NEQ. Moreover, for the anxiety, depression, and stress subscales, only the anxiety subscale influenced nighttime eating problems due to increased sleep problems, which in turn increased the difficulty of morning sleepiness and falling asleep at night.

Conclusion

Consequently, depression and stress directly increased nighttime eating problems. Anxiety exacerbates eating problems, both directly and indirectly, through sleep. Behavioral and psychological interventions to reduce anxiety, depression, and stress may be helpful strategies for the treatment of night eating syndrome.

Level of evidence: Level IV

\section{Introduction}

Night eating syndrome used to be a little known eating disorder. With the prevalence of obesity and increased research into obesity, it has gained attention. Night eating syndrome is now included in the Otherwise Specified Feeding section and Eating Disorders of the fifth revision of the Diagnostic and Statistical Manual of Mental Disorders [1]. There are three basic diagnostic criteria. The first is eating at least $25 \%$ of the daily food intake after dinner or eating $\geq 2$ nights per week. The second criterion is that this binge eating is intentional. The third criterion must include at least three of the following: These include morning anorexia, a strong urge to eat between dinner and sleep or at night, insomnia, a belief that eating is necessary to induce or regain sleep, or a worsening of mood in the evening [2-4].

It is important to distinguish night eating syndrome from other eating disorders, sleep-related eating disorders (SRED) [5]. The NES characterizes SRED by awareness during the nighttime binge eating episode. In sleep-related eating disorders, people do not realize that they are getting up at night and eating. However, people with night eating disorders are conscious during eating. People with SRED have been found to sleepwalk in the past or during current investigations. Other sleep disorders such as restless legs syndrome, periodic sleep movements, and obstructive sleep apnea may also be found in individuals with SRED [5].

Although pointing out the importance of distinguishing people with nocturnal eating syndrome from sleep-related eating disorders, people with nocturnal eating syndrome may have other sleep disorders. In studies conducted with people with nocturnal eating syndrome, these individuals have been found to have some sleep disorders such as insomnia and falling asleep late [6, 7]. Disruptions in circadian sleep patterns are particularly noted in people with NES [8]. This finding also proves to be a strategy in the treatment of nocturnal eating disorder. In people diagnosed with nocturnal eating syndrome, changes in the circadian phase and amplitude of melatonin, cortisol, leptin, ghrelin, insulin, and glucose rhythms can be detected [9]. Studies addressing the treatment of NES indicate that cognitive-behavioral therapies and medications affecting the serotonin system may be inadequate in treatment [10-12]. Therefore, given the finding of delays in circadian rhythms, chronobiological therapies have emerged as an option in recent years [13, 14]. Two case reports using 14-day morning 30-minute sessions of 10,000 lux white light therapy suggest the efficacy of light therapy in the treatment of NES [13].

In addition to studies examining the relationship between NES and sleep, there are studies examining the relationship between NES and mood. For example, studies on night eating syndrome have shown that stress exacerbates the clinical condition and reducing stress reduces night eating episodes [11]. Depressive moods also show frequent comorbidity with NES [11] [15]. In individuals with NES, depressed mood patterns are less detectable in the evening and at night [8]. Some studies using depression scales also reported significantly higher scores in individuals with nocturnal eating syndrome than in those without $[16,11]$. Individuals with NES also have lower self-esteem and more severe anxiety symptoms [15]. It is a stress-related disorder, and some studies have also found stress-related neuroendocrine changes such as increased cortisol levels [17]. 
In the literature, there are studies on the relationship between sleep and NES, mood disorders and NES. In this study, the three variables are examined simultaneously.

Considering the literature, we conclude that mood disorders, sleep disorders, and nocturnal eating problems are related. Therefore, the aim of our study was to investigate the direct and indirect effects of sleep disturbances and mood problems on nocturnal eating disorders. Based on this premise, we formulated the following hypotheses:

\section{Hypothesis 1}

Sleep quality will be related to NES.

\section{Hypothesis 2}

Anxiety, depression, and stress directly increase NES.

\section{Hypothesis 3}

Anxiety, depression, and stress will mediate the relationship between sleep quality and NES.

\section{Method}

\section{Participants and procedure}

This web-based cross-sectional study included a sample of 171 adolescents aged 12-18 years and was conducted in July 2021 . The study protocol was approved by the ethics committee. Informed consent was obtained from all participants via the study website.

\section{Data collection}

The questionnaire contained demographic information: Gender, age, and body mass index. Of 196 participants who answered the questions, 171 completed the questionnaire. Participants who did not complete the questionnaire or gave invalid responses were excluded. The data instruments, specifically the questionnaires, were administered to male and female adolescents.

Depression, Anxiety, and Stress Scale - 21 Items (DASS-21) is a self-report scale designed to measure depression, anxiety, and stress [18]. There are three subscales, each consisting of seven items. The depression scale assesses dysphoria, hopelessness, the worthlessness of life, selfworthlessness, disinterest, listlessness, and sluggishness. The Anxiety Scale assesses autonomic arousal, situational anxiety, feelings of anxiety, and skeletal muscle effects. The stress scale assesses nervous arousal and mild excitability, irritability/over reactivity and impatience, difficulty relaxing, and how one feels. The depression, anxiety and stress scores are calculated by adding the scores of the corresponding items. The Turkish validity and reliability study was conducted by Sarıçam et al.[19].

The Night Eating Questionnaire (NEQ): This is a screening questionnaire consisting of 14 questions developed by Allison et al [2]. The questionnaire includes questions about morning appetite and first food intake of the day, evening and nighttime eating, frequency of eating after dinner, food cravings, control of nighttime eating, difficulty falling asleep and frequency of nighttime awakenings, alertness, and mood during nighttime eating. All participants complete the first nine questions of the questionnaire. Participants who do not wake up at night or do not snack will be directed to continue with the following questions. Questions 10-12 will be completed by participants who wake up at night, and questions 13 and 14 will be completed by participants who eat snacks at night. Except for the seventh item of the questionnaire, all items are rated with a five-point Likert measure ranging from 0 to 4 . The seventh item asks about mood changes during the day and those who do not notice any changes during the day score 0 . The total score can range from 0-52. The Turkish validity and reliability study was conducted by Atasoy et al [20].

SCOPA Sleep Scale; It is a 12-item scale developed by Marinus et al. in 2003 to assess sleep problems (such as difficulty falling asleep in the past month, inability to fall asleep, fall asleep very quickly, or stay awake) and sleep quality in Parkinson Disease patients [21]. It consists of 12 items, five items assessing night sleep, six items assessing daytime sleepiness, and 1 item assessing general sleep quality. For the subdimensions of night sleep and daytime sleepiness, there are response options ranging from 0 to 3 . For the sub-dimension that asks about general sleep quality with one item, seven different response options ranging from 0 to 6 items can be given. The Turkish validity and reliability study was conducted by Sonmez et al. [22]. Although the scale was developed for Parkinson's patients, it was used because its questions contain general concepts.

\section{Statistical Analysis}

We used SPSS 21.0 to examine correlations and descriptive statistics. We estimated mediation effects through structural equation modeling (SEM) using AMOS. We used a bootstrapping procedure to test the statistical significance of the paths and indirect effects of each model. We assessed model fit using several fit indices, including the ratio of chi-squared to degrees of freedom ( $\mathrm{X} 2 / \mathrm{df})$, the comparative fit index (CFI), the 
root mean square error of approximation (RMSEA), and the standardized root mean square residual (SRMR). The SEM literature suggests that model fit is excellent when $\chi 2 / d f \leq 3, C F I \geq 0.95$, RMSEA $\leq 0.05$, and SRMR $\leq 0.08[23,24]$.

\section{Results}

Of the 171 adolescents who participated in this study, 94 (55.0\%) were girls and 77 (45.0\%) were boys with a mean age of $15.15 \pm 1.52$ years. The mean and standard deviation of body weight and BMI of the adolescents are shown in Table 1.

In examining the correlation of the scales completed by the adolescents, it was found that the morning anorexia subscale of the NEQ had no significant correlation with the anxiety, depression, and stress subscales of the DASS 21 and also had no correlation with the daytime sleepiness and nighttime sleep subscales of the SCOPA Sleep Scale. The Hyperphagia in the Evening subscale of the NEQ correlated with the Depression, Anxiety, and Stress subscales and with the Daytime Sleepiness and Nighttime Sleep subscales of the SCOPA Sleep Scale. In contrast, the Nocturnal Ingestions subscale was not meaningfully related to anxiety, but was significantly associated with depression and stress scores on the DASS 21. NEQ total score was related to all scales, but not to BMI $(p<0.05)$ (Table 2).

A linear regression analysis was performed to examine the relationship between the NEQ and the DASS 21 and the daytime sleepiness and nighttime sleep subscales of the SCOPA Sleep Scale. It was found that increased stress, worsening of depressive symptoms, and difficulty falling asleep had a significant relationship with nighttime eating $(p<0.05)($ Table 3$)$.

When the relationship between the nighttime sleep subscales of the SCOPA Sleep Scale and other variables was evaluated using the linear regression model, a significant association was found between falling asleep with anxiety symptoms, evening hyperphagia, and total NEQ score $(p<0.05)$ (Table 4).

In addition to the many studies that have examined the association between sleep disturbances and nighttime eating disorders, in the current study we examined whether anxiety, depression, and stress directly and indirectly influence nighttime eating disorders. We followed a stepwise method to construct the optimal model for the mediated effects of anxiety, depression, and stress. First, we assessed the fit of the parallel mediation model (Model 1), which included the following: (a) direct pathway of waking difficulty, sleep quality $\rightarrow$ NEQ score, (b) indirect pathway of anxiety, depression, and stress $\rightarrow$ waking difficulty, sleep quality $\rightarrow$ NEQ score (summary of model fit: $\chi 2 / \mathrm{df}=39.17, \mathrm{CFI}=1.00, \mathrm{RMSEA}=$ 0.3222 , and SRMR $=0.394$. The pathway anxiety $\rightarrow$ waking difficulty, sleep quality $\rightarrow$ NEQ score was significant (Fig. 1 ).

Anxiety $(\mathrm{p}=0.012$ and $95 \% \mathrm{Cl}[0.083,0.344])$.

Depression ( $p=0.558$ and $95 \% \mathrm{Cl}[-0.092,0.219])$.

Stress $(p=0.296$ and $95 \% \mathrm{Cl}[-0.062,0.145])$.

\section{Discussion}

In this study, we aimed to advance research on the association between sleep quality and nocturnal eating disorders. Specifically, we examined whether the association between sleep quality and eating disorders could be explained by the indirect effects of anxiety, depression, and stress. The results provided several noteworthy findings.

No correlation was found between morning anorexia and the SCOPA sleep scale and the DASS 21. The Evening hyperphagia subscale of the NEQ had a significant positive correlation with the depression and stress subscales of the DASS 21 and the insomnia and Daytime Sleepiness subscales of the SCOPA Sleep Scale. This finding confirms our hypothesis that sleep and mood disturbances may have a direct effect on nocturnal eating disorder. The literature on the presence of stress and increase in depressive symptoms associated with an increase in night eating behaviors was also confirmed in this study $[11,8,17]$. The significant increase in insomnia and daytime sleepiness scores in individuals who eat more at night is also consistent with the literature [8,7]. Nocturnal ingestion had a significant correlation with DASS 21 depression and Stress Scale, but not anxiety.

When analyzed with the linear regression model, the NEQ score was significantly associated with the stress and depression subscales of the DASS 21 scale and was reliable. NEQ scores were also significantly related to the problem of falling asleep at night and not to daytime sleepiness. The data obtained from the studies are consistent with publications showing an increase in insomnia and an excess of stress and depression in individuals with nocturnal eating problems $[6,4]$.

In our second hypothesis, we stated that anxiety, depression, and stress can directly influence sleep disturbances. In our first hypothesis, it was found that sleep disturbances can directly lead to eating disorders. A linear regression analysis was performed to determine the direct relationships. When the relationship between the total score of the SCOPA sleep scale and the other scales is evaluated using linear regression, it 
can be concluded that increases in the anxiety score are associated with increased sleep problems. A significant correlation was also found with the NEQ total score.

In addition to the direct effects of anxiety, depression, and stress on NEQ, AMOS path analysis was used to examine whether they have an indirect effect on NEQ, which is the main object of the study. Of the anxiety, depression, and stress subscales, only the anxiety subscale influenced the nighttime eating problem by increasing the sleep problem. Anxiety exacerbated both the morning sleepiness problem and the nighttime falling asleep problem. NEQ was already significantly associated with sleep problems. Consequently, depression and stress directly exacerbated nighttime eating problems. Anxiety exacerbated eating problems both directly and indirectly through sleep.

\section{Strength and limits}

This study aimed to examine how sleep quality was related to night eating syndrome via the effects of anxiety, depression, and stress to determine the mechanism of its development. We believe that our study makes a significant contribution to the literature because we found that anxiety, depression, and stress directly influenced the Night Eating Questionnaire scores. We also found that depression and stress increased nighttime eating. Additionally, anxiety influenced nighttime eating problems due to increased sleep problems. This increased morning sleepiness and difficulty falling asleep at night. Compared to many studies that have examined the association between sleep disturbances and nighttime eating disorders, in the current study, we examined whether anxiety, depression, and stress directly and indirectly influenced nighttime eating disorders. Although our study contributes to the literature, it has some significant limitations. First, due to the cross-sectional analysis, causal and temporal relationships cannot be precisely determined. Longitudinal and experimental studies are required to confirm the causal mechanisms. Second, the generalizability of the study was limited due to the small sample size. Future studies should use a broader sample and replicate this study. Third, data collection in this study was made based on self-report via the Internet limited objectivity. The use of objective methods, such as actigraphy, to determine sleep disturbance would be more helpful in generalizing the results of this study.

What is already known on this subject? Many studies have shown the relationship between mood disorders and sleep disorders, and night eating syndrome.

What this study adds? In addition to the literature information, this study adds the following conclusion as new information. Unlike depression and stress, an anxiety disorder may increase night-eating syndrome because it increases sleep disorder. Anxiety may contribute to the relationship between sleep disorder and night eating disorder.

\section{Declarations}

\section{Funding}

No funding was used for this study.

\section{Data sharing and declaration}

The data supporting the findings of this study are available upon reasonable request from the corresponding author.

\section{Conflict of interest}

There is no conflict of interest.

\section{Ethical Approval}

Research procedures complied with universal ethical standards and the tenets of the Helsinki Declaration of 1975, as revised in 2000. Ethics Committee of the Bolu Izzet Baysal Training and Research Hospital, Bolu, Turkey approved the study by the protocol number $227 / 2021$. Informed consent was obtained from all participants via the survey website

\section{References}

1. Edition F (2013) Diagnostic and statistical manual of mental disorders. Am Psychiatric Assoc 21

2. Allison KC, Lundgren JD, O'Reardon JP, Martino NS, Sarwer DB, Wadden TA, Crosby RD, Engel SG, Stunkard AJ (2008) The Night Eating Questionnaire (NEQ): psychometric properties of a measure of severity of the Night Eating Syndrome. Eating behaviors 9 (1):62-72

3. Allison KC, Stunkard AJ, Thier SL (2004) Overcoming night eating syndrome: a step-by-step guide to breaking the cycle. New Harbinger Publications, 
4. Allison KC, Lundgren JD, O'Reardon JP, Geliebter A, Gluck ME, Vinai P, Mitchell JE, Schenck CH, Howell MJ, Crow SJ (2010) Proposed diagnostic criteria for night eating syndrome. International Journal of Eating Disorders 43 (3):241-247

5. Mansukhani MP, Kolla BP, Ramar K (2014) International classification of sleep disorders 2 and American Academy of Sleep Medicine practice parameters for central sleep apnea. Sleep Medicine Clinics 9 (1):1-11

6. Manni R, Ratti MT, Tartara A (1997) Nocturnal eating: prevalence and features in 120 insomniac referrals. Sleep 20 (9):734-738

7. Rogers NL, Dinges DF, Allison KC, Maislin G, Martino N, O'Reardon JP, Stunkard AJ (2006) Assessment of Sleep in Women With Night Eating Syndrome. Sleep 29 (6):814-819. doi:10.1093/sleep/29.6.814

8. O'reardon JP, Ringel BL, Dinges DF, Allison KC, Rogers NL, Martino NS, Stunkard AJ (2004) Circadian eating and sleeping patterns in the night eating syndrome. Obesity research 12 (11):1789-1796

9. Goel N, Stunkard AJ, Rogers NL, Van Dongen HPA, Allison KC, O'Reardon JP, Ahima RS, Cummings DE, Heo M, Dinges DF (2009) Circadian Rhythm Profiles in Women with Night Eating Syndrome. Journal of Biological Rhythms 24 (1):85-94. doi:10.1177/0748730408328914

10. Kelly C. Allison, Ph.D. * „Jennifer D. Lundgren, Ph.D. \# „Reneé H. Moore, Ph.D. „ John P. O’Reardon, M.D. „Albert J. Stunkard, M.D. (2010) Cognitive Behavior Therapy for Night Eating Syndrome: A Pilot Study. American Journal of Psychotherapy 64 (1):91-106.

doi:10.1176/appi.psychotherapy.2010.64.1.91

11. O'Reardon JP, Stunkard AJ, Allison KC (2004) Clinical trial of sertraline in the treatment of night eating syndrome. International Journal of Eating Disorders 35 (1):16-26

12. O'Reardon JP, Allison KC, Martino NS, Lundgren JD, Heo M, Stunkard AJ (2006) A randomized, placebo-controlled trial of sertraline in the treatment of night eating syndrome. The American journal of psychiatry 163 (5):893-898. doi:10.1176/ajp.2006.163.5.893

13. Friedman S, Even C, Dardennes R, Guelfi JD (2004) Light therapy, nonseasonal depression, and night eating syndrome. Canadian Journal of Psychiatry 49 (11):790

14. Friedman S, Even C, Dardennes R, Guelfi JD (2002) Light Therapy, Obesity, and Night-Eating Syndrome. American Journal of Psychiatry 159 (5):875-876. doi:10.1176/appi.ajp.159.5.875

15. Gluck ME, Geliebter A, Satov T (2001) Night eating syndrome is associated with depression, low self-esteem, reduced daytime hunger, and less weight loss in obese outpatients. Obesity research 9 (4):264-267

16. Napolitano MA, Head S, Babyak MA, Blumenthal JA (2001) Binge eating disorder and night eating syndrome: psychological and behavioral characteristics. International Journal of Eating Disorders 30 (2):193-203

17. Birketvedt GS, Florholmen J, Sundsfjord J, Østerud B, Dinges D, Bilker W, Stunkard A (1999) Behavioral and neuroendocrine characteristics of the night-eating syndrome. Jama $282(7): 657-663$

18. Henry JD, Crawford JR (2005) The short-form version of the Depression Anxiety Stress Scales (DASS-21): Construct validity and normative data in a large non-clinical sample. British journal of clinical psychology 44 (2):227-239

19. Sarıçam H (2018) The psychometric properties of Turkish version of Depression Anxiety Stress Scale-21 (DASS-21) in health control and clinical samples.

20. Atasoy N, Saraçlı Ö, Konuk N, Ankarali H, Guriz SO, Akdemir A, Sevinçer GM, Atik L (2013) Gece Yeme Anketi-Türkçe Formunun psikiyatrik ayaktan hasta popülasyonunda geçerlilik ve güvenilirlik çalışması.

21. Marinus J, Visser M, van Hilten JJ, Lammers GJ, Stiggelbout AM (2003) Assessment of sleep and sleepiness in Parkinson disease. Sleep 26 (8):1049-1054

22. Sönmez N (2018) Scopa uyku ölçeği Türkçe versiyonunun geçerliliği ve güvenirliliği. Namık Kemal Üniversitesi,

23. Hoyle RH, Isherwood JC (2013) Reporting results from structural equation modeling analyses in Archives of Scientific Psychology. Archives of scientific psychology 1 (1):14

24. Kline RB (2015) Principles and practice of structural equation modeling. Guilford publications,

\section{Tables}


Table 1 Descriptive statistics of all variables $(\mathrm{N}=171)$

$$
\text { mean SD }
$$

Age, years

$\begin{array}{ll}15.15 & 1.53 \\ 61.56 & 16.4\end{array}$

Weight, (kg)

$165.81 \quad 11.15$

Height (cm)

$$
22.1
$$

$\mathrm{BMI} \mathrm{kg} / \mathrm{m}^{2}$

\begin{tabular}{lllll} 
& \multicolumn{2}{l}{ Female } & \multicolumn{2}{l}{ Male } \\
& N & $\%$ & & \\
& & & N & $\%$ \\
\hline Gender & 94 & 55 & 77 & 45 \\
\hline
\end{tabular}

Values are reported as mean; SD, standard deviation.

BMI, Body Mass Index 
Table 2 Correlations among all variables $(\mathrm{N}=171)$$$
1
$$

$4 \quad 5 \quad 6$

6

7

8

9

10

11

12

DASS 21-

Anxiety 1

DASS $21 \quad 0.619 * *$

Stress 2

\begin{tabular}{llll}
$\begin{array}{l}\text { DASS 21 } \\
\text { Depression } 3\end{array}$ & $0.633^{\star *}$ & $0.681^{\star *}$ & \\
\hline $\begin{array}{l}\text { SCOPA- } \\
\text { Nighttime } \\
\text { sleep 4 }\end{array}$ & $0.435^{\star *}$ & $0.271^{\star *}$ & $0.307^{\star *}$ \\
\hline
\end{tabular}

\begin{tabular}{|c|c|c|c|c|c|c|c|c|}
\hline $\begin{array}{l}\text { Daytime } \\
\text { sleepiness }\end{array}$ & 0.376 ** & 0.367 ** & $0.369 * \star$ & 0.436 ** & & & & \\
\hline BMI 6 & 0.088 & $0.188 *$ & -0.031 & 0.082 & 0.136 & & & \\
\hline $\begin{array}{l}\text { Morning } \\
\text { anorexia } 7\end{array}$ & 0.018 & 0.092 & 0.135 & 0.096 & 0.077 & $-0.201 * *$ & & \\
\hline $\begin{array}{l}\text { Evening } \\
\text { hyperphagia } \\
8\end{array}$ & $0.280 \star \star$ & $0.284^{\star \star}$ & $0.233^{* *}$ & 0.039 & $0.254^{\star *}$ & 0.143 & -0.096 & \\
\hline Mood/ sleep & 0.450 ** & 0.467 ** & $0.546^{\star \star}$ & $0.569 * \star$ & $0.350 * *$ & 0.149 & $0.203^{* \star}$ & 0.053 \\
\hline
\end{tabular}

9

\begin{tabular}{|c|c|c|c|c|c|c|c|c|c|c|c|}
\hline $\begin{array}{l}\text { Nocturnal } \\
\text { ingestions } 10\end{array}$ & 0.144 & $0.254^{\star \star}$ & $0.162^{\star}$ & $0.283^{\star *}$ & $0.294^{\star *}$ & 0.095 & -0.013 & $0.245^{\star \star}$ & $0.242^{\star \star}$ & & \\
\hline $\begin{array}{l}\text { NEQ total } \\
\text { score } 11\end{array}$ & $0.457 * \star$ & $0.525^{\star \star}$ & 0.538 ** & $0.511^{\star *}$ & $0.445^{\star \star}$ & 0.133 & $0.349 * *$ & 0.470 ** & $0.815^{\star \star}$ & $0.581^{\star *}$ & \\
\hline scoPA sleep & $0.479 * *$ & $0.377^{\star *}$ & $0.399 * \star$ & $0.849 * *$ & $0.846^{\star *}$ & 0.128 & 0.103 & $0.173^{\star}$ & $0.543^{\star *}$ & $0.341^{\star *}$ & $0.564^{\star \star}$ \\
\hline
\end{tabular}
cale total score 12

*, $p<0.05$ **, $p<0.01$

DASS 21, Depression, Stress and Anxiety Scale; NEQ, Night Eating Questionnaire; BMI, Body Mass Index 
Table 3 Linear Regression of Night Eating Questionnaire Total Scores with other variables

Standardized Coefficients $\quad t \quad$ P $\quad 95,0 \%$ Confidence Interval for B

Beta

Lower Bound Upper Bound VIF

\begin{tabular}{|c|c|c|c|c|c|c|c|}
\hline \multirow[t]{3}{*}{ DASS21 } & Anxiety & -0.047 & -0.578 & 0.564 & -0.235 & 0.129 & 2.087 \\
\hline & Stress & 0.244 & 2.946 & $0.004^{\star \star}$ & 0.093 & 0.47 & 2.132 \\
\hline & Depression & 0.25 & 2.991 & $0.003^{\star \star}$ & 0.094 & 0.458 & 2.184 \\
\hline \multirow[t]{2}{*}{ ScOPA sleep scale } & Daytime sleepiness & -0.186 & -1.727 & 0.086 & -0.642 & 0.043 & 3.628 \\
\hline & Nighttime sleep & 0.553 & 4.911 & $<0.001^{\star \star}$ & 0.312 & 0.732 & 3.948 \\
\hline
\end{tabular}

Dependent Variable: Night Eating Questionnaire

*, $p<0.05 * *, p<0.01$

DASS 21, Depression, Stress and Anxiety Scale

Table 4 Linear Regression of Nighttime Sleep Subscale of the SCOPA Sleep with other variables

\begin{tabular}{|c|c|c|c|c|c|c|c|}
\hline & & \multirow{2}{*}{$\begin{array}{l}\text { Standardized } \\
\text { Coefficients } \\
\text { Beta }\end{array}$} & \multirow[t]{2}{*}{$t$} & \multirow[t]{2}{*}{ p } & \multicolumn{3}{|c|}{$95.0 \%$ Confidence Interval for B } \\
\hline & & & & & $\begin{array}{l}\text { Lower } \\
\text { Bound }\end{array}$ & $\begin{array}{l}\text { Upper } \\
\text { Bound }\end{array}$ & VIF \\
\hline \multirow[t]{4}{*}{ DASS21 } & Anxiety & 0.361 & 4.293 & $<0.001 * \star$ & 0.138 & 0.373 & 1.969 \\
\hline & Stress & -0.13 & -1.456 & 0.147 & -0.222 & 0.034 & 2.217 \\
\hline & Depression & -0.113 & -1.222 & 0.223 & -0.205 & 0.048 & 2.392 \\
\hline & Morning anorexia & -0.172 & -2.359 & $0.02 *$ & -0.776 & -0.069 & 1.473 \\
\hline \multicolumn{8}{|l|}{$\begin{array}{l}\text { Night Eating } \\
\text { Questionnaire }\end{array}$} \\
\hline & $\begin{array}{l}\text { Evening } \\
\text { hyperphagia }\end{array}$ & -0.344 & -4.724 & $<0.001^{\star \star}$ & -0.809 & -0.332 & 1.471 \\
\hline & $\begin{array}{l}\text { Nocturnal } \\
\text { ingestions }\end{array}$ & -0.061 & -0.747 & 0.456 & -0.419 & 0.189 & 1.831 \\
\hline & NEQ total score & 0.732 & 6.371 & $<0.001^{\star *}$ & 0.317 & 0.602 & 3.663 \\
\hline
\end{tabular}

Dependent Variable: SCOPA sleep scale

*, $p<0.05 * *, p<0.01$

DASS 21, Depression, Stress and Anxiety Scale; NEQ, Night Eating Questionnaire 
Figures

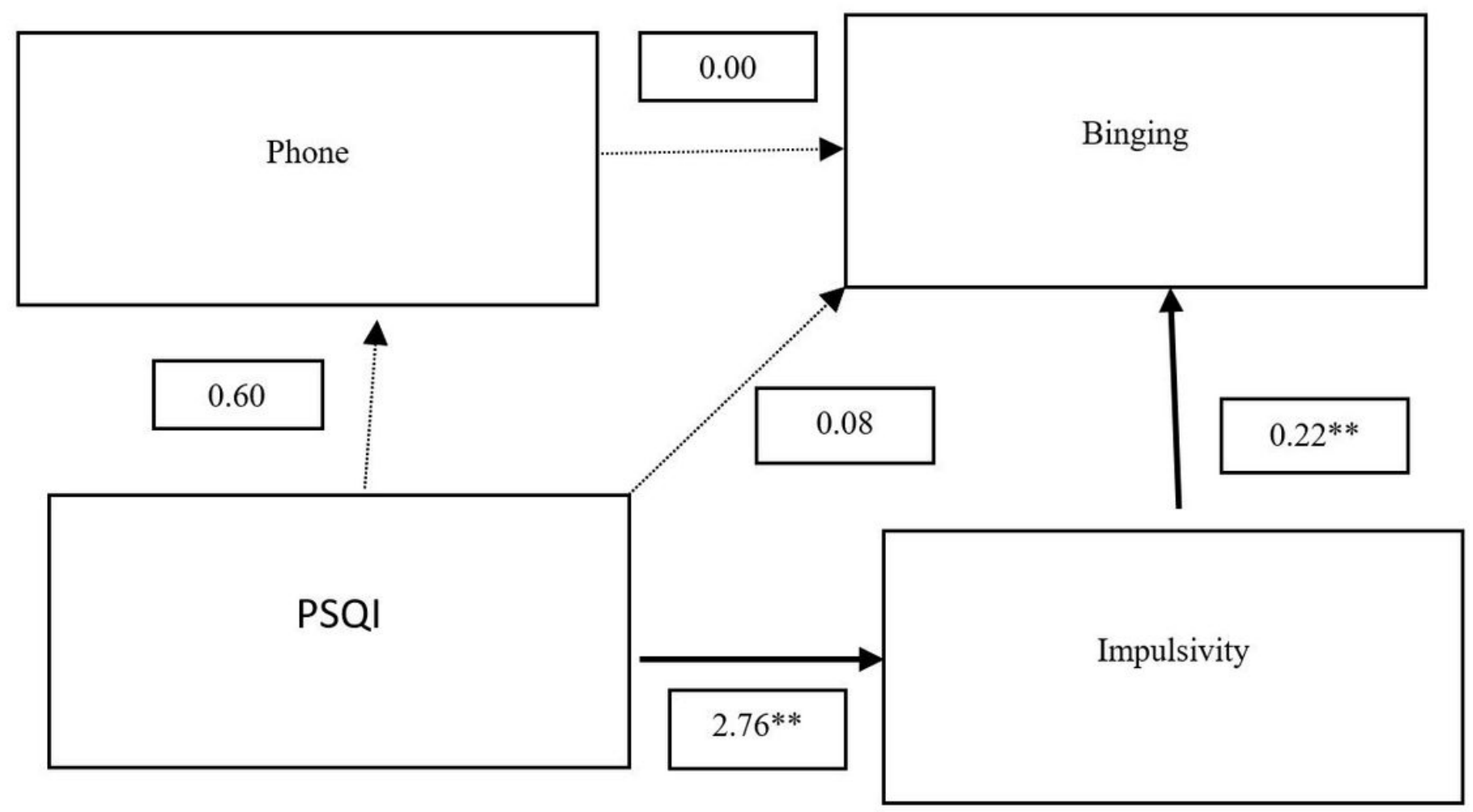

Figure 1

Tests of Model 1 showed parallel indirect effects of impulsivity and problematic mobile phone usage in the association between poor sleep quality and binging.

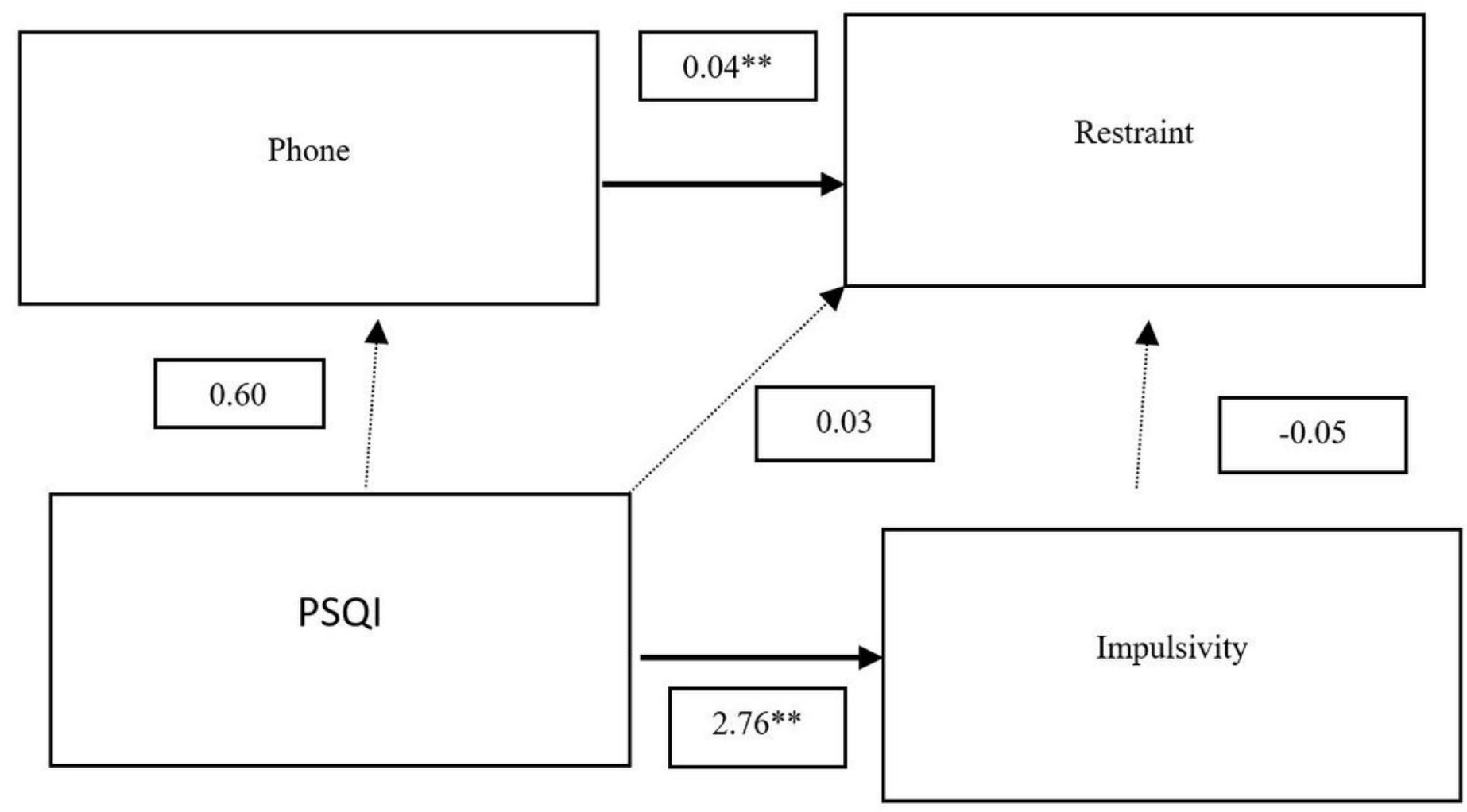


Figure 2

Tests of Model 2 showed parallel indirect effects of impulsivity and problematic mobile phone usage in the association between poor sleep quality and restraint.

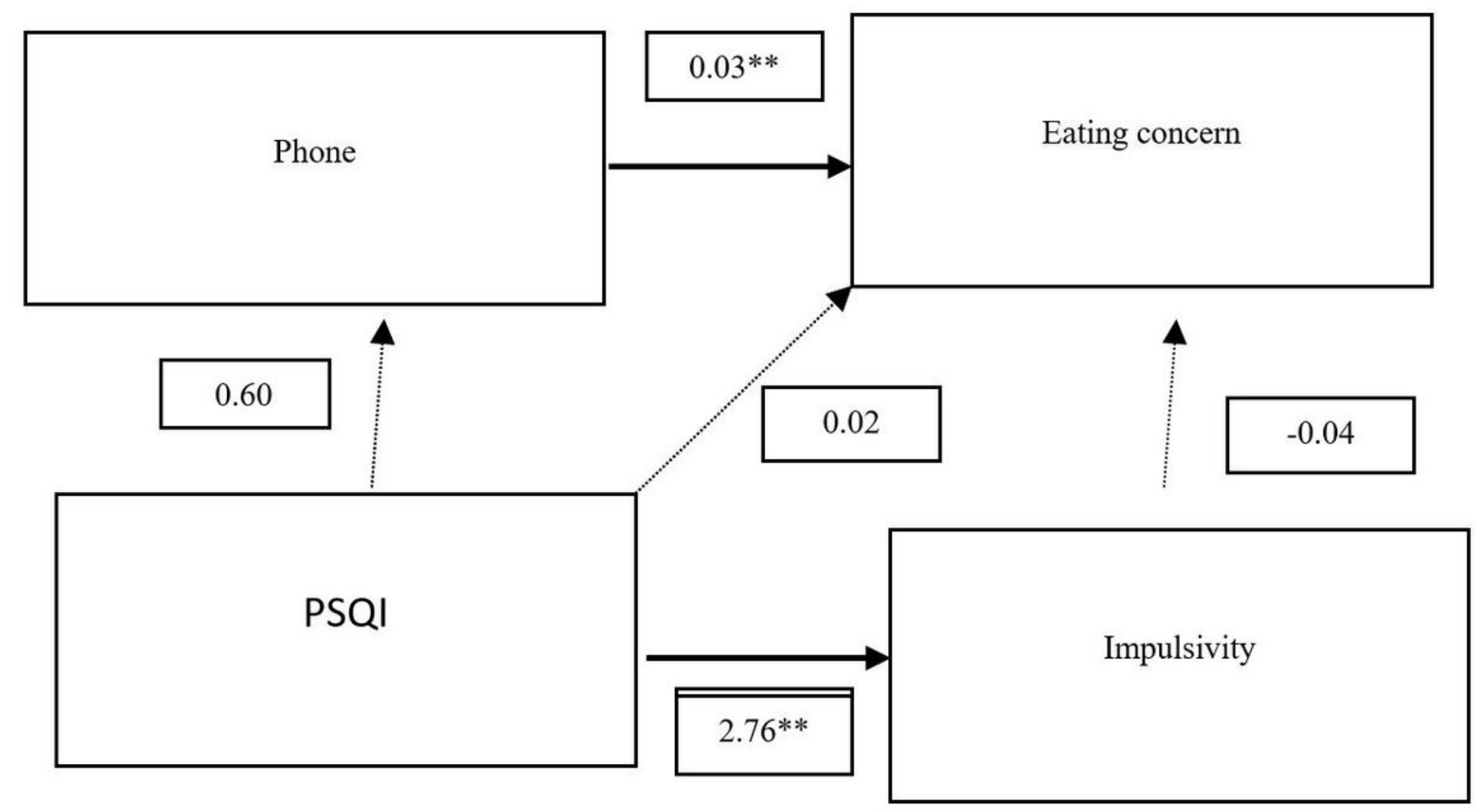

Figure 3

Tests of Model 3 showed parallel indirect effects of impulsivity and problematic mobile phone usage in the association between poor sleep quality and eating concern. 


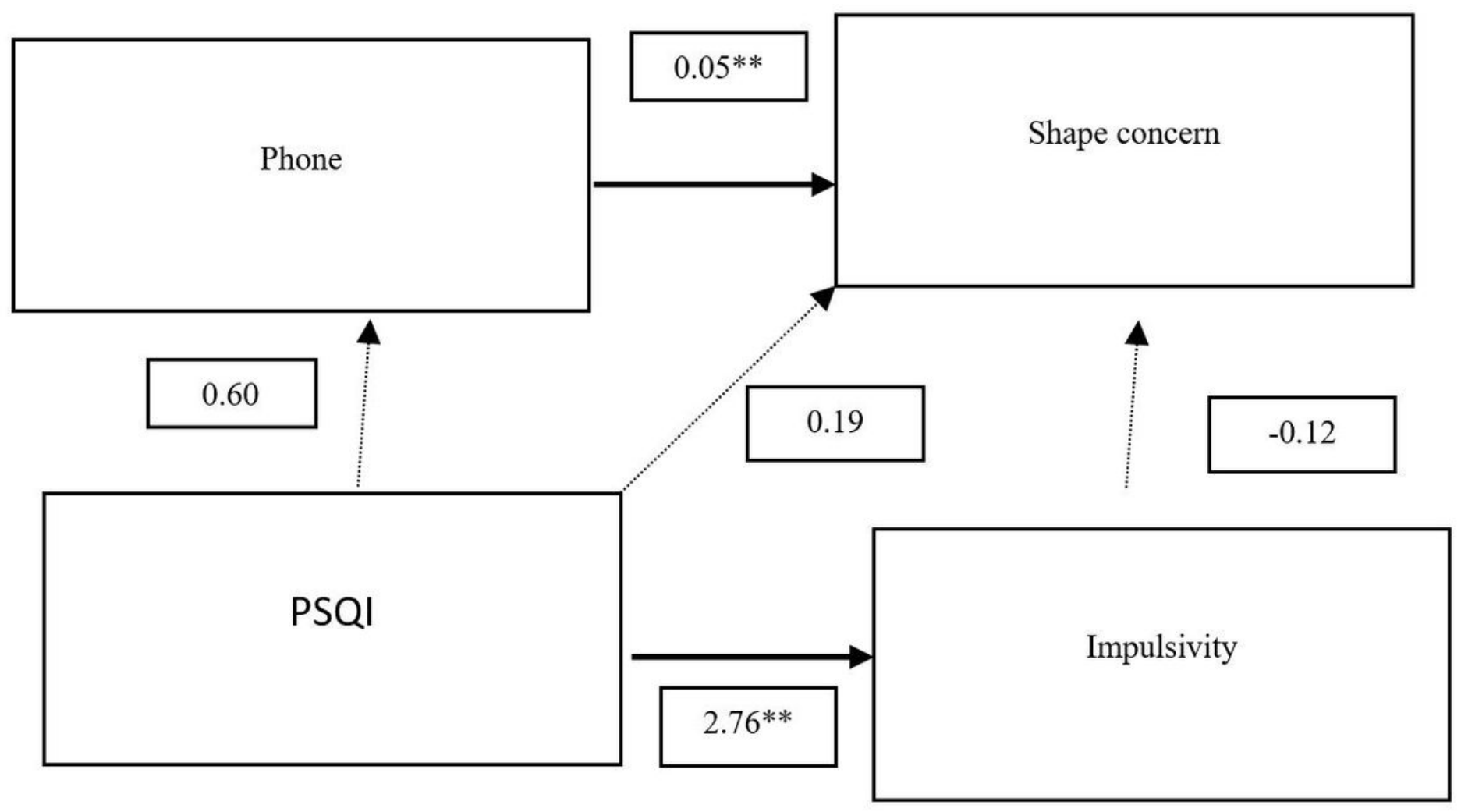

Figure 4

Tests of Model 4 showed parallel indirect effects of impulsivity and problematic mobile phone usage in the association between poor sleep quality and shape concern.

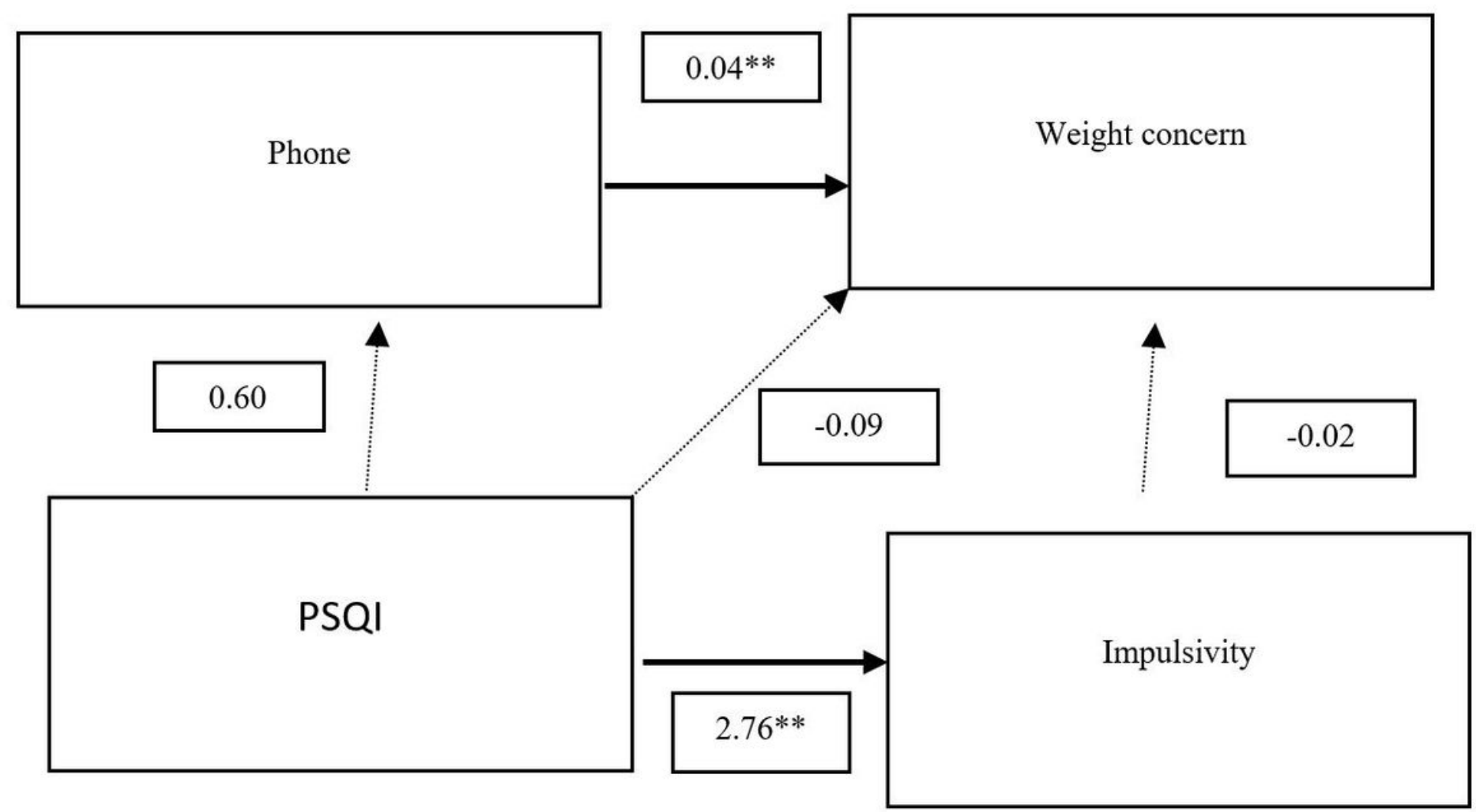

Figure 5 
Tests of Model 5 showed parallel indirect effects of impulsivity and problematic mobile phone usage in the association between poor sleep quality and weight concern.

\section{Supplementary Files}

This is a list of supplementary files associated with this preprint. Click to download.

- renamedf2266.docx 